\title{
The level of specific lgE is a moderate predictor for the outcome of a double-blind placebo- controlled food challenge for hazelnut in children
}

\author{
Laury Masthoff ${ }^{*}$, Suzanne Pasmans ${ }^{2}$, Mirjam Knol ${ }^{3}$, Els van Hoffen ${ }^{1}$, Annebeth Flinterman ${ }^{1}$, Petra Kentie ${ }^{4}$, \\ André Knulst ${ }^{1}$, Yolanda Meijer ${ }^{4}$
}

From Food Allergy and Anaphylaxis Meeting 2011

Venice, Italy. 17-19 February 2011

Literature about the value of diagnostic tests for hazelnut allergy in children is scarce. For peanut allergy cutoff levels of specific IgE with a 95\% positive predictive value (PPV) were published. To evaluate current diagnostics for hazelnut allergy in children, data of 151 children, who underwent a double-blind placebo-controlled food challenge (DBPCFC) for hazelnut were analyzed. The PPV or negative predictive value (NPV) of the level of specific IgE (CAP) for hazelnut and the size of the skin prick test (SPT) for hazelnut was determined. The influence of spiking of the CAP for hazelnut with rCor a 1 was analyzed. The level of specific IgE for hazelnut was a moderate predictor for a positive DBPCFC for hazelnut. No cutoff levels of specific IgE for hazelnut with a 95\% PPV could be determined. Before Cor a 1 spiking the maximum reached PPV was $73 \%$ for a cutoff level of $26 \mathrm{kUA} / \mathrm{L}$, after spiking the maximum reached PPV was $64 \%$ for a cutoff level of $31 \mathrm{kUA} / \mathrm{L}$. The spiking increased the NPV from $91 \%$ to $100 \%$ for a cutoff level of $0.35 \mathrm{kUA} / \mathrm{L}$. SPT was a better predictor for a positive DBPCFC compared to the level of specific IgE. When the SPT $>16 \mathrm{~mm}$, the PPV was $100 \%$. By combining both tests, the PPV reached 100\% when the level of specific IgE for hazelnut was $>5 \mathrm{kUA} / \mathrm{L}$ and the level of SPT was $>12 \mathrm{~mm}$. However, the PPV of $100 \%$ for SPT alone and the combination of CAP and SPT accounted for only $11 \%$ respectively $13 \%$ of the children undergoing a DBPCFC for hazelnut. So, the level of specific IgE and reactivity of SPT are moderate predictors for the outcome of a DBPCFC for hazelnut in children.

'University Medical Center Utrecht, (Pediatric) Dermatology/Allergology, Utrecht, Netherlands

Full list of author information is available at the end of the article
New diagnostic tools are needed to replace the DBPCFC which is burdensome, expensive and limited available.

\section{Author details}

${ }^{1}$ University Medical Center Utrecht, (Pediatric) Dermatology/Allergology, Utrecht, Netherlands. ${ }^{2}$ University Medical Center Utrecht, (Pediatric) Dermatology/Allergology, Center of Pediatric Allergology, Wilhelmina Children's Hospital, Pediatric Pulmonology, Utrecht, Netherlands. ${ }^{3}$ University Medical Center Utrecht, Julius Center for Health Sciences and Primary Care, Utrecht, Netherlands. ${ }^{4}$ University Medical Center Utrecht, Center of Pediatric Allergology, Wilhelmina Children's Hospital, Pediatric Pulmonology, Utrecht, Netherlands.

Published: 12 August 2011

doi:10.1186/2045-7022-1-S1-037

Cite this article as: Masthoff et al:: The level of specific lgE is a moderate predictor for the outcome of a double-blind placebocontrolled food challenge for hazelnut in children. Clinical and Translational Allergy 2011 1(Suppl 1):O37.

Submit your next manuscript to BioMed Central and take full advantage of:

- Convenient online submission

- Thorough peer review

- No space constraints or color figure charges

- Immediate publication on acceptance

- Inclusion in PubMed, CAS, Scopus and Google Scholar

- Research which is freely available for redistribution 